Saudi Journal of Oral and Dental Research

Abbreviated Key Title: Saudi J Oral Dent Res ISSN 2518-1300 (Print) |ISSN 2518-1297 (Online) Scholars Middle East Publishers, Dubai, United Arab Emirates Journal homepage: http://scholarsmepub.com/sjodr/

Review Article

\title{
Novel Bone Grafting Techniques in Implant Dentistry
}

Dr. Navneet Kaur ${ }^{* *}$, Dr. Kavitha Ragavan MDS $^{2}$, Dr. Amit Shivakant Vathare MDS ${ }^{3}$, Dr. Rishabh Bhanot ${ }^{4}$, Dr. Anas Abdul Khader ${ }^{5}$, Dr. V K Sasank Kuntamukkula MDS ${ }^{6}$

${ }^{1}$ Reader, Department of oral and maxillofacial surgery, Guru Nanak Dev Dental College \& RI, Sunam, Punjab India

${ }^{2}$ Consultant Oral \& Maxillofacial Surgery, Ernakulum, Kerala India

${ }^{3}$ Prosthodontist \& Implantologist, Jaysingpur, Shirol, Kolhapur, Maharashtra India

${ }^{4}$ Consultant Oral and Maxillofacial surgeon, SRCJC Hospital, Ludhiana

${ }^{5}$ Associate professor, Department of Periodontology, Azeezia Dental College, Quilon, Kerala India

${ }^{6}$ Assistant Professor, Department of Oral and Maxillofacial Surgery, Sri Sai College of Dental Surgery, Vikarabad, India

DOI: $10.36348 /$ sjodr.2019.v04i11.003 $\quad$ | Received: 02.11.2019| Accepted: 14.11.2019| Published: 25.11 .2019

*Corresponding author: Dr. Navneet Kaur

\section{Abstract}

Ideal rehabilitation with the aid of dental implants is reliant on the presence of adequate bone volume and quality at the edentulous area. Various surgical techniques for bone grafting both in the form of natural and synthetic graft materials have been industrialized to enhance successful placement of dental implants in resorbed alveolar ridge. This review throws light on the numerous novel bone grafting techniques for dental implants.

Keywords: Bone grafts, Dental Implants, Novel Techniques.

Copyright @ 2019: This is an open-access article distributed under the terms of the Creative Commons Attribution license which permits unrestricted use, distribution, and reproduction in any medium for non-commercial use (NonCommercial, or CC-BY-NC) provided the original author and source are credited.

\section{INTRODUCTION}

In clinical scenarios where oral rehabilitation needs to be performed with the aid of dental implants, a narrow residual alveolar ridge poses a great challenge to the operator. Many surgical approaches have been advocated but the ideal and the most frequently employed method is bone grafting [1].

\section{Minimally Invasive Tunnel Technique}

It is considered to be a safe, simple and patient compliance method to augment bone. The subperiosteal tunneling approach is a minimally invasive procedure that allows the surgeon to allocate the graft in a space that is obtained between the soft tissues and the underlying bone through an access represented by a single incision on the mesial limit of the bone defect [2, 3]. This approach is believed to warrant minimal discomfort to the patient in the immediate postoperative phase in addition to ensuring a steady coverage of the graft during the healing time, with minimal risk of exposure, infection, and failure [4,5]. The subperiosteal tunneling technique is considered superior to other bone grafting techniques since it uses autologous bone, which is still considered the gold standard for bone regeneration [6]. Flap necrosis and wound dehiscence are the two major problems in bone grafting surgery. They both contribute to uncover of the graft with subsequent infection of the surgical site and failure of the surgical procedure.
There are several advantages of this technique compared to the conventional bone grafting techniques. This technique is relatively less morbid and less technique sensitive, and it does not require flap elevation. Since there is no flap elevation, it ensures better preservation of keratinized gingiva, and adequate overfilling is also possible since primary coverage is not directly required. Furthermore, it ensures minimal implant exposure and infection that result in good mechanical stability of bone graft material and to prevent post-operative complications.

\section{Bone manipulation techniques}

These techniques are capable of manipulating the bone to alter their density to make it exceedingly durable and strong. These techniques mobilize vital bone with plastic bending, shaping, or condensation of tissue as a bone flap or bone-periosteal flap [7]. This results in contour or dimensional changes, while preserving bone integrity and viability. Current techniques include inlay and onlay grafting, guided bone regeneration (GBR), bone expansion, bone splitting osteotomy, and different fixation devices such as bone screws, pins, titanium mesh, different augmentation materials, and different barrier membranes[8].

\section{Bone expansion technique}

This technique involves the manipulation of the bone to form a receptor site for an implant without 
the removal of any bone from the patient [9]. This technique maintains the existing soft bone by pushing the buccal bony plates of the residual ridge laterally with minimal trauma. This technique takes the advantage of the softer bone quality found in Types III and IV maxillary bone by relocating the alveolar bone rather than losing the precious bone by drilling [10]. The most common anatomic area in which ridge expansion is performed is in the narrow anterior maxilla, followed by posterior maxilla and then the anterior and posterior mandible, respectively.

\section{Alveolar ridge splitting technique}

This techniques is performed by gaining access to a ridge that is $<3 \mathrm{~mm}$ wide by splitting the buccal and palatal bone flaps with a scalpel first by separating two cortices through its cancellous bone. This technique is employed in cases where there is an insufficient width to utilize round osteotomes. This procedure provides a quicker method wherein an atrophic ridge can be predictably expanded and grafted with bone allografts, eliminating the need for a second donor site and a second stage surgery [11]. Ideal sites to perform this procedure include clinical scenarios where there is a knife-edge ridge that widens further apically, and that consists of adequate cortical thickness but with some degree of interpositional lamellar bone. This is particularly true in the anterior region of the maxilla.

\section{Guided bone regeneration}

It is also known as "membrane protected bone regeneration." The concept of GBR implies the use of cell-occlusive membranes for space provision over a vertical or horizontal defect, promoting the in-growth of osteogenic cells while preventing migration of undesired cells from the overlying soft tissue [12]. It also effectively stabilizes the blood coagulum and thereby allows for faster healing to occur. This technique can be used before or at the same time as implant placement.

\section{Growth factors}

Numerous growth factors have been widely tested in animal models. Amongst these, bone BMPs are considered to be unique as they induce osteogenic precursor cells into osteogenic cells and have shown incredible bone growth in many animals and also human clinical studies. Other growth factors besides BMPs that have been implicated during bone regeneration are also being investigated, including platelet-derived growth factor, transforming growth factor- $\beta$, insulin-like-growth factor-1, vascular endothelial growth factor, and fibroblast growth factor, among others [13].

\section{Autogenous teeth}

Autogenous bone is considered an ideal material for the reconstruction of hard tissue defects, due to its ability to promote osteogenesis, osteoinduction, osteoconduction, and enhanced healing, but it does induce immune rejection. On the contrary, the harvest volume is limited, resorption is unavoidable, and a second defect is induced in the donor area. Considering these confines, allogeneic bone, xenogeneic bone, and synthetic bone have evolved in clinical practice [14]. Few researchers used extracted teeth as bone grafting material [15].

The chemical composition of teeth is very similar to that of bone. Approximately $90 \%$ of the organic material present in the dentin consists of collagen fibers, primarily type I collagen, and these fibers play an important role in calcification. The remaining organic components consist of noncollagenous proteins, carbohydrate, lipid, citrate, lactate, etc [16]. Diverse bone growth factors, including bone morphogenetic protein, are known to be present in the protein fraction [15]. The autologous teeth bone grafting material contains both inorganic and organic material, and the major component of the inorganic material contains 4 types of calcium phosphate. Histologic examination of the autologous teeth grafting area revealed that the grafting material was gradually resorbed and replaced with new bone. The new bone formed a direct union with the remaining autologoue teeth graft [15].

\section{Alveolar distraction osteogenesis}

A recent advancement to bone augmentation procedure is callus distraction osteogenesis. After its widespread use in long bones \& facial bones, distraction osteogenesis has been used in the residual alveolus of maxilla and mandible. With the aid of distraction osteogenesis, bone can be augmented vertically or horizontally in the residual alveolar ridges. The process of distraction avoids bone grafting procedures from other body parts and its associated complications. It has also an added advantage of recreation of soft tissues along with the hard tissues [17]. Complications associated with the procedure are malposed distracted segment, bone defects formation, fracture of transport segment and infections leading to failure [18].

A recent study concluded that alveolar vertical distraction osteogenesis is a dependaple and predictable method for both hard and soft tissue genesis. Vertically bone can be augmented more than $10 \mathrm{~mm}$ without the use of bone transplantation, thus reducing the morbidity with this technique. The bone gain reached at the end of distraction appeared to be lasting and the infection rate is extremely limited. Most of the complications confronted are easy to resolve. Implants placement is feasible with primary stability in neogenerated bone at the level of the distracted areas [19].

\section{CONCLUSION}

This review of literature draws to a conclusion that there aret a wide range of surgical procedures can be used to correct deficient edentulous ridges. Based on 
Navneet Kaur et al; Saudi J Oral Dent Res, Nov., 2019; 4(11): 767-769

the existing literature, it is challenging to conclude that one surgical procedure offers a better outcome than another, as far as predictability of the augmentation and survival/success rates of implants placed in the augmented sites are concerned. Every surgical technique poses its own benefits and hindrances, which must be carefully evaluated before the surgical intervention.

It is still unclear as to whether some surgical procedures that are widely used in clinical practice, such as sinus grafting procedures in the case of limited/moderate sinus pneumatization or reconstruction of atrophic edentulous mandibles with onlay autogenous bone grafts, are really useful for improving the long-term survival of implants. Based on the literature it can advocated that in order to understand when bone augmentation procedures are needed and which are the most effective techniques for the specific clinical indications, larger, well-designed, long-term trials are needed. It is difficult to provide clear indications with respect to which procedures are actually needed. Priority should be given to procedures that are simpler and less invasive, involve less risk of complications, and reach their goals within the shortest time frame

\section{REFERENCES}

1. McAllister, B. S., \& Haghighat, K. (2007). Bone augmentation techniques. Journal of periodontology, 78(3), 377-396.

2. Borgonovo, A. E., Marchetti, A., Vavassori, V., Censi, R., Boninsegna, R., \& Re, D. (2013). Treatment of the atrophic upper jaw: rehabilitation of two complex cases. Case reports in dentistry, 2013.

3. Hasson, O. (2007). Augmentation of deficient lateral alveolar ridge using the subperiosteal tunneling dissection approach. Oral Surgery, Oral Medicine, Oral Pathology, Oral Radiology, and Endodontology, 103(3), e14-e19.

4. Maestre-Ferrín, L., Boronat-López, A., PeñarrochaDiago, M., \& Peñarrocha-Diago, M. (2009). Augmentation procedures for deficient edentulous ridges, using onlay autologous grafts: an update. Med Oral Patol Oral Cir Bucal, 14(8), e402-7.

5. De Macedo, L. G. S., de Macedo, N. L., \& Monteiro, A. D. S. F. (2009). Fresh-frozen human bone graft for repair of defect after adenomatoid odontogenic tumour removal. Cell and tissue banking, 10(3), 221-226.

6. Khan, S. N., Cammisa Jr, F. P., Sandhu, H. S., Diwan, A. D., Girardi, F. P., \& Lane, J. M. (2005). The biology of bone grafting. JAAOS-Journal of the American Academy of Orthopaedic Surgeons, 13(1), 77-86.
7. Cullum, D. (2010). Advances in bone manipulation: Part 2. Osteomobilization for horizontal and vertical implant site development. SORMS, 18, 1-44.

8. Simion, M., Baldoni, M., \& Zaffe, D. (1992). Jawbone enlargement using immediate implant placement associated with a split-crest technique and guided tissue regeneration. International Journal of Periodontics \& Restorative Dentistry, 12(6).

9. Borgner, R. A., Kirkos, L. T., Gougaloff, R., Cullen, M. T., \& Delk, P. L. (1999). Computerized tomography scan interpretation of a bone expansion technique. Journal of Oral Implantology, 25(2), 102-108.

10. Siddiqui, A. A., \& Sosovicka, M. (2006). Lateral bone condensing and expansion for placement of endosseous dental implants: a new technique. Journal of Oral Implantology, 32(2), 8794.

11. Demetriades, N., Park, J. I., \& Laskarides, C. (2011). Alternative bone expansion technique for implant placement in atrophic edentulous maxilla and mandible. Journal of Oral Implantology, 37(4), 463-471.

12. Rodriguez, R., Hartmann, N., \& Weingart, D. (2015). Current concepts of bone regeneration in implant dentistry. Journal of Surgery [Jurnalul de chirurgie ], 10(4), 263-265.

13. Dimitriou, R., Tsiridis, E., \& Giannoudis, P. V. (2005). Current concepts of molecular aspects of bone healing. Injury, 36(12), 1392-1404.

14. Kima, S. G., Yeoa, H. H., \& Kimb, Y. K. (1999). Grafting of large defects of the jaws with a particulate dentin-plaster of Paris combination. Oral Surgery, Oral Medicine, Oral Pathology, Oral Radiology, and Endodontology, 88(1), 22-25.

15. Kim, Y. K., Kim, S. G., Byeon, J. H., Lee, H. J., Um, I. U., Lim, S. C., \& Kim, S. Y. (2010). Development of a novel bone grafting material using autogenous teeth. Oral Surgery, Oral Medicine, Oral Pathology, Oral Radiology, and Endodontology, 109(4), 496-503.

16. Min, B. M. (2007). Oral biochemistry. Seoul: Daehan Narae Publishing, 8-73.

17. Rachmiel, A., Srouji, S., \& Peled, M. (2001). Alveolar ridge augmentation by distraction osteogenesis. International journal of oral and maxillofacial surgery, 30(6), 510-517.

18. Saulačić, N., Martín, M. S., Camacho, M. D. L. A. L., \& García, A. G. (2007). Complications in alveolar distraction osteogenesis: A clinical investigation. Journal of oral and maxillofacial surgery, 65(2), 267-274.

19. Mohanty, R., Kumar, N. N., \& Ravindran, C. (2015). Vertical alveolar ridge augmentation by distraction osteogenesis. Journal of Clinical and Diagnostic Research: JCDR, 9(12), ZC43. 